\title{
A possible role for inflammation in mediating apoptosis of oligodendrocytes as induced by the Lyme disease spirochete Borrelia burgdorferi
}

\author{
Geeta Ramesh', Shemi Benge ${ }^{2}$, Bapi Pahar ${ }^{3}$ and Mario T Philipp ${ }^{1 *}$
}

\begin{abstract}
Background: Inflammation caused by the Lyme disease spirochete $B$. burgdorferi is an important factor in the pathogenesis of Lyme neuroborreliosis. Our central hypothesis is that $B$. burgdorferi can cause disease via the induction of inflammatory mediators such as cytokines and chemokines in glial and neuronal cells. Earlier we demonstrated that interaction of B. burgdorferi with brain parenchyma induces inflammatory mediators in glial cells as well as glial (oligodendrocyte) and neuronal apoptosis using ex vivo and in vivo models of experimentation.

Methods: In this study we evaluated the ability of live B. burgdorferi to elicit inflammation in vitro in differentiated human MO3.13 oligodendrocytes and in differentiated primary human oligodendrocytes, by measuring the concentration of immune mediators in culture supernatants using Multiplex ELISA assays. Concomitant apoptosis was quantified in these cultures by the in situ terminal deoxynucleotidyl transferase mediated UTP nick end labeling (TUNEL) assay and by quantifying active caspase-3 by flow cytometry. The above phenomena were also evaluated after $48 \mathrm{~h}$ of stimulation with B. burgdorferi in the presence and absence of various concentrations of the anti-inflammatory drug dexamethasone.

Results: B. burgdorferi induced enhanced levels of the cytokine IL- 6 and the chemokines IL-8 and CCL2 in MO3.13 cells as compared to basal levels, and IL-8 and CCL2 in primary human oligodendrocytes, in a dose-dependent manner. These cultures also showed significantly elevated levels of apoptosis when compared with medium controls. Dexamethasone reduced both the levels of immune mediators and apoptosis, also in a manner that was dose dependent.

Conclusions: This finding supports our hypothesis that the inflammatory response elicited by the Lyme disease spirochete in glial cells contributes to neural cell damage. As oligodendrocytes are vital for the functioning and survival of neurons, the inflammation and subsequent apoptosis of oligodendrocytes induced by B. burgdorferi could contribute to the pathogenesis of Lyme neuroborreliosis.
\end{abstract}

Keywords: Lyme neuroborreliosis, Borrelia burgdorferi, Oligodendrocytes, CCL2/MCP-1, IL-6, IL-8, Apoptosis, Active caspase-3, Dexamethasone

\section{Background}

Lyme neuroborreliosis (LNB) in the US is manifest in $10 \%$ to $15 \%$ of patients diagnosed with Lyme disease [1,2]. In addition to the classical neurological triad of meningitis, cranial neuritis, and radiculitis, LNB may also manifest, albeit more rarely, as encephalopathy, encephalomyelitis $[3,4]$, and cerebellitis [5]. Acute transverse myelitis, caused by inflammatory processes of the spinal cord resulting in

\footnotetext{
* Correspondence: philipp@tulane.edu

'Division of Bacteriology and Parasitology, Tulane National Primate Research Center, Covington, LA, USA

Full list of author information is available at the end of the article
}

axonal demyelination, has also been reported in LNB patients [6-9]. In the peripheral nervous system (PNS), Lyme disease appears as neuritis with patchy multifocal axonal degeneration associated with epineural perivascular inflammation [10,11].

LNB patients may experience a wide array of neurological and neuropsychiatric symptoms as a result of white matter inflammation that results in a subacute multiple sclerosis (MS)-like manifestation [12,13]. Brain magnetic resonance imaging (MRI) of LNB patients that was suggestive of a demyelinating disease, with MS-like symptoms that responded well to antibiotic therapy, has been reported 
[14,15]. It has been hypothesized that B. burgdorferi may exacerbate MS or be a trigger for an MS-like inflammatory demyelinating disease of the central nervous system (CNS) by activating myelin-specific $\mathrm{T}$ cells via molecular mimicry $[16,17]$, or by bystander activation via inflammatory cytokines [16].

Encephalitis associated with LNB involves white matter more often than gray matter $[4,18,19]$. Inflammatory lesions in the brain and spinal cord show multifocal encephalitis with large areas of demyelination in perivascular white matter commonly associated with the presence of B. burgdorferi DNA [6,20-22]. Astroglial and neuronal proteins, anti-myelin antibodies and cells secreting antibodies to myelin basic protein have been detected in the cerebrospinal fluid (CSF) of patients with LNB, indicating possible glial and neuronal damage in the CNS parenchyma [23-25]. There is evidence that B. burgdorferi spirochetes can adhere to neurons, CNS glia, and Schwann cells from studies in neuronal and glial cell lines and primary rat brain cultures [26], and that B. burgdorferi can adhere to and perhaps invade human neuroglial and cortical neuronal cells [27]. Adhesion was found to be associated with galactocerebroside, a glycolipid component of myelin, and oligodendrocytes in primary brain cultures were shown to be damaged, by scanning electron microscopy $[26,28,29]$. Cells that secrete antibodies to myelin basic protein have been found in CSF of patients with LNB, suggesting damage to oligodendrocytes possibly as a result of demyelination [24].

Cytokines and chemokines are key immune mediators that play an important role in promoting CNS injury in various kinds of inflammatory neurodegenerative diseases [30-34]. Various inflammatory cytokines and chemokines have been reported in the CSF of patients with LNB [35-38].

We hypothesize that $B$. burgdorferi can cause disease via the induction of inflammatory mediators such as cytokines and chemokines in glial and neuronal cells. Earlier we demonstrated that interaction of B. burgdorferi with brain parenchyma induces inflammatory mediators in glial cells as well as glial (oligodendrocyte) and neuronal apoptosis [39]. Further, we found that a similar inflammatory response occurs in vivo, as demonstrated in rhesus monkeys inoculated intrathecally with live $B$. burgdorferi. This resulted in elevation of IL-6, IL-8, CCL2, and CXCL13 in the CSF within 1 week post infection, accompanied with histopathological changes consistent with acute neurological Lyme disease such as leptomeningitis and radiculitis, as well as satellite glial cell and neuronal apoptosis in the dorsal root ganglia [40].

Here we assessed the ability of live B. burgdorferi to elicit inflammatory mediators in cultures of differentiated human MO3.13 oligodendrocytes [41], and primary cultures of differentiated human oligodendrocyte precursor cells (HOPC). Further, we examined the ability of live B. burgdorferi to induce apoptosis of oligodendrocytes, and quantified apoptosis in the above cultures by the in situ TUNEL assay, and by measuring activated caspase- 3 by flow cytometry. The role of inflammation in mediating apoptosis of oligodendrocytes, as induced by $B$. burgdorferi was studied by evaluating the above phenomena after $48 \mathrm{~h}$ of stimulation with $B$. burgdorferi in the presence and absence of various concentrations of the anti-inflammatory drug dexamethasone, a glucocorticoid used in the treatment of immune-mediated inflammatory diseases [42].

\section{Methods}

Maintenance and differentiation of MO3.13 cultures

The human oligodendrocyte cell line MO3.13 was obtained from CELLutions Biosystems Inc. (Burlington, Ontario, Canada). Cells were revived as per the manufacturer's instructions and maintained in complete growth medium (CGM) consisting of Dulbecco's minimal essential medium (DMEM) (high glucose) (Invitrogen, Carlsbad, CA), 10\% fetal bovine serum (ThermoFisher, Waltham, MA, USA), and antibiotics, 100 units of penicillin and $100 \mu \mathrm{g}$ of streptomycin $(\mathrm{P} / \mathrm{S})$ (Invitrogen), in a humidified incubator with an atmosphere of $5 \% \mathrm{CO}_{2}$, set at $37^{\circ} \mathrm{C}$. Cells were maintained in CGM for 3 days, after which the medium was replaced by differentiation medium (DM), consisting of DMEM, P/S, and phorbol 12-myristate 13-acetate (Sigma, St. Louis, MO, USA), at a concentration of $100 \mathrm{nM}$, and devoid of serum. Cells were cultured in DM for 4 days, after which time they were used in experiments.

MO3.13 cells were also seeded in Lab-Tek II CC ${ }^{2}$ chamber slides containing two wells (Nunc, Rochester, NY, USA) at a density of $0.5 \times 10^{4}$ cells per well, and maintained in $2 \mathrm{~mL}$ CGM followed by DM as described above for the purpose of evaluating phenotypic markers using immunofluorescence staining and confocal microscopy, as well as for evaluation of apoptosis by the in situ TUNEL assay. Typically, the final cell count in chamber slides after maintenance in CGM for 3 days followed by DM for 4 days was $2.5 \times 10^{4}$ cells per well. Cells were seeded into six-well plates at a seeding density of $2 \times 10^{4}$ cells per well for evaluation of inflammatory mediators and for flow cytometry experiments. Typically, the final cell density after differentiation in six-well plates was $2.5 \times 10^{5}$ cells per well. Only differentiated MO3.13 cells were used for estimation of inflammatory mediators or for the evaluation of apoptosis, described below.

\section{Human oligodendrocyte precursor cells (HOPC)}

HOPC were cultured on poly-L-Lysine coated chamber slides containing two wells at a seeding density of $8 \times 10^{4}$ cells per well, as recommended by the provider (ScienCell Inc., Carlsbad, CA, USA). Cells were revived by thawing cultures as per the manufacturer's instructions and maintained 
in 'precursor medium' for 8 days, after which they were maintained in 'differentiation medium' for 3 days prior to commencing experiments. Both media were supplied by the manufacturer, and their composition is proprietary. The final cell count after differentiation was comparable to the initial seeding density. The HOPC differentiated into mature cells with longer cell processes, as indicated by the manufacturer. Differentiated HOPC maintained on poly-L-Lysine-coated chamber slides were used for the evaluation of both secreted immune mediators as well as apoptosis by the in situ TUNEL assay.

\section{Stimulation of differentiated MO3.13 oligodendrocytes and HOPC cultures with live $B$. burgdorferi for evaluation of immune mediators and apoptosis}

B. burgdorferi strain B31 5A19 passage 3 was grown in Barbour-Stoenner-Kelly-H (BSK-H) medium, supplemented with $6 \%$ rabbit serum (Sigma, St. Louis, MO, USA) and antibiotics (rifampicin at $45.4 \mathrm{mg} / \mathrm{mL}$, phosphomycin at $193 \mathrm{mg} / \mathrm{mL}$ and amphotericin at $0.25 \mathrm{mg} / \mathrm{mL}$ ) to late logarithmic phase under microaerophilic conditions. Spirochetes were pelleted at $2000 \mathrm{x} \mathrm{g}$ for $30 \mathrm{~min}$ at RT. At the end of the run the rotor was left to coast without breaking so as to minimize damage to the live spirochetes. The differentiated MO3.13 cultures were washed in DM devoid of $\mathrm{P} / \mathrm{S}$. The B. burgdorferi culture was washed twice using phosphate buffered saline (PBS) pH 7.2 (Invitrogen, Grand Island, NY, USA) and resuspended in DM at a concentration so as to achieve the desired multiplicity of infection (MOI). Controls with no spirochetes were also included. Cultures were incubated for $48 \mathrm{~h}$ in a humidified $5 \% \mathrm{CO}_{2}$ incubator, set at $37^{\circ} \mathrm{C}$. At the 48 -h time point culture supernatants were collected for evaluation of inflammatory mediators. Culture supernatants were centrifuged at $4^{\circ} \mathrm{C}$ at $2000 \mathrm{x} \mathrm{g}$ for $30 \mathrm{~min}$ to remove any suspended bacteria and the supernatant was aliquoted and stored at $-80^{\circ} \mathrm{C}$ until used. The oligodendrocyte cultures were then fixed in $2 \%$ paraformaldehyde as described below for assessment of apoptosis. Spirochetes remained motile after 48-h incubation in MO3.13 or HOPC differentiation medium. Assessment of motility after incubation in MO3.13 differentiation medium required re-culturing spirochetes in BSK-H.

\section{Immunofluorescence staining and confocal microscopy}

MO3.13 cells were either held in CGM for 3 days or further incubated in DM for 4 days for evaluation of phenotypic markers pre- and post-differentiation, respectively. Only differentiated HOPC cultures were used for evaluation of phenotypic markers.

Medium was removed and cells were fixed in $2 \%$ paraformaldehyde in PBS (PFA) (USB, Cleveland, $\mathrm{OH}$, USA) at RT for 10 min with gentle rocking on a rocker in the dark. PFA was removed with three washes using PBS, each for $5 \mathrm{~min}$ at $\mathrm{RT}$ on the rocker. Cells were then given a post-fixation permeabilization treatment using a mixture of ethanol:acetic acid (2:1) (Sigma) for $5 \mathrm{~min}$ at $-20^{\circ} \mathrm{C}$. Cells were washed thrice with PBS as described above. The slides were then detached from the chamber by placing the chambers in 70\% methanol for $10 \mathrm{~min}$ and following the manufacturer's instructions (Nunc). Detached slides were transferred to slide holders containing PBSFSG-TX-100 buffer (phosphate-buffered saline pH 7.4 containing $0.2 \%$ fish skin gelatin (Sigma), and $0.02 \%$ Triton X-100 (MP Biomedicals, Solon, OH, USA), and 0.02\% sodium azide (Sigma), and held in this buffer for $15 \mathrm{~min}$ with gentle rocking at RT for permeabilization, followed by a rinse with PBS-FSG (phosphate-buffered saline containing $0.2 \%$ fish skin gelatin and $0.02 \%$ sodium azide). Slides were then blocked in a buffer consisting of PBS containing 10\% normal goat serum (Invitrogen) and 0.02\% sodium azide (NGS) for $1 \mathrm{~h}$ in a humidified chamber at RT, followed by incubation with respective primary antibodies; rabbit polyclonal anti-human myelin basic protein (MBP) Clone AB 980 at 1:100 (Millipore, Billerica, MA, USA), or mouse monoclonal IgG1 anti-human glial fibrillary acidic protein (GFAP), Clone G-A-5 at 1:200 (Sigma). Relevant isotype controls (Sigma) at the same concentrations as their respective primary antibodies were also included.

All primary antibodies at the appropriate concentrations were left on the slides for $1 \mathrm{~h}$ at RT, in a humidifying box. The slides were then rinsed with PBS-FSG-TX-100 buffer and then held in this buffer for $5 \mathrm{~min}$, followed by a rinse with PBS-FSG buffer. The relevant secondary antibodies, either goat anti-mouse or goat anti-rabbit (Invitrogen) at a dilution of 1:1000 in NGS, were applied to the slides and left in the humidified dark slide-box at RT for 30 to $45 \mathrm{~min}$. Secondary antibodies were conjugated to one of the Alexa fluorochromes- Alexa 488 (green) or 568 (red). Slides were washed and rinsed as described above and then incubated with a nuclear stain TOPRO-3 (Invitrogen) at 1:1000 in NGS for $15 \mathrm{~min}$. After a final wash in PBS-FSG-TX-100 buffer followed by a rinse in PBS-FSG, slides were mounted in anti-quenching medium (Sigma). The stained and mounted slides were stored in the dark at $4^{\circ} \mathrm{C}$ until they were viewed under a confocal microscope. MO3.13 cultures were evaluated for the expression of MBP as well as GFAP, while HOPC cells were only stained for the evaluation of MBP expression. Slides with MO3.13 and HOPC oligodendrocytes were also stained with isotype controls for the primary antibodies at protein concentrations used for the respective primary antibodies.

Confocal microscopy was performed using a Leica TCS SP2 confocal microscope equipped with three lasers (Leica Microsystems, Exton, PA, USA). Images of individual channels were merged to obtain images containing all channels. Photoshop CS3 (Adobe systems Inc., San Jose, CA, USA) was used to assign colors to each fluorochrome. 


\section{Evaluation of immune mediators from culture supernatants}

The concentrations of cytokines and chemokines present in the culture supernatants were quantified using the Human 14-plex Cytokine-Chemokine Array kit (Millipore), following the manufacturer's instructions. The analytes detected by this panel are: $\mathrm{Hu}$ IL- $1 \beta$, Hu IL-2, Hu IL-4, Hu IL-5, Hu IL-6, Hu IL-7, Hu IL-8, Hu IL-10, $\mathrm{Hu}$ IL-12 (p70), Hu IL-13, Hu GMCSF, Hu IFN- $\gamma, \mathrm{Hu}$ CCL2, and $\mathrm{Hu}$ TNF- $\alpha$. The multiplex plate was read using a Bio-Plex 200 Suspension Array Luminex System (Bio-Rad, Hercules, CA, USA).

\section{Evaluation of apoptosis by in situ TUNEL assay}

Cells contained in chamber slides were labeled for MBP by immunofluorescence staining as described above. Slides were then fixed with 2\% PFA, washed three times with PBS by rinsing slides in PBS and holding them in PBS for 2 min between washes. Slides were then subjected to the TUNEL ApopTagPlus fluorescein in situ apoptosis assay (Chemicon, Temecula, CA, USA) as per the manufacturer's instructions. Slides were then mounted as described above and stored at $4^{\circ} \mathrm{C}$ in the dark until viewed. The percentage of apoptotic oligodendrocytes from 10 fields was evaluated from each chamber area by counting the total number of MBP-positive cells (at least 500 cells) from each of the chamber areas, followed by the number of cells that showed co-localization of both the TUNEL signal and MBP expression. All counts were made by viewing slides under a fixed magnification of $63 \times$ (corresponding to an area of $0.05 \mathrm{~mm}^{2}$ ) using the confocal microscope.

\section{Evaluation of the role of inflammation in mediating oligodendrocyte apoptosis using the anti-inflammatory drug dexamethasone}

MO3.13 cell cultures were seeded as described above in chamber slides for evaluation of apoptosis or in six-well plates for evaluation of immune mediators, and maintained in growth and differentiation medium as described. Prior to stimulation with live B. burgdorferi, differentiated cultures were incubated with various concentrations of dexamethasone (water soluble), $5 \mu \mathrm{M}, 15 \mu \mathrm{M}$, and 150 $\mu \mathrm{M}$ (Sigma) for $24 \mathrm{~h}$ at $37^{\circ} \mathrm{C}$, after which they were washed and then incubated in fresh differentiation medium containing the respective concentrations of dexamethasone and live B. burgdorferi at a MOI of 10:1 at $37^{\circ}$ $\mathrm{C}$ for $48 \mathrm{~h}$ and devoid of P/S. Similar concentrations of dexamethasone as those mentioned above have been reported to inhibit the production of CCL2 in mice microglia [43]. Dexamethasone is supplied as a water-soluble formulation consisting of dexamethasone and a carrier substance (2-hydroxypropyl)- $\beta$-cyclodextrin. The effect of the carrier alone, at the respective molar concentrations accompanying dexamethasone was assessed by incubating
MO3.13 oligodendrocytes as described above in the presence and absence of B. burgdorferi and carrier alone at 15, 45 , and $450 \mu \mathrm{M}$, respectively.

After $48 \mathrm{~h}$, culture supernatants were collected and processed for evaluation of inflammatory mediators, and cells were fixed and evaluated for apoptosis by the in situ TUNEL assay as described above. Medium controls that were pretreated and then incubated with the same respective concentrations of dexamethasone but without the addition of live B. burgdorferi were also included. The effect of dexamethasone on differentiated HOPC was also evaluated as described above.

\section{Evaluation of expression of MBP and active caspase- 3 by immunofluorescence staining and flow cytometry}

Differentiated MO3.13 cell cultures that were maintained in six-well plates and were stimulated with $B$. burgdorferi at a MOI of 10:1 for $48 \mathrm{~h}$ in DM devoid of $\mathrm{P} / \mathrm{S}$ were used in this experiment. Most of the medium covering the cells was removed and centrifuged gently at $300 \mathrm{x} \mathrm{g}$ for $10 \mathrm{~min}$ to collect any cells that were dislodged due to cell death. This cell pellet was combined with the cells harvested after trypsinization for $3 \mathrm{~min}$ at $37^{\circ} \mathrm{C}$. The cells were washed with PBS and pelleted at $1800 \mathrm{rpm}$ for $10 \mathrm{~min}$ at RT, and used for staining for $\mathrm{MBP}$ and active caspase-3 as described below.

For flow cytometry staining of MBP, cells harvested from the various conditions were distributed into aliquots of cell suspensions adjusted to a cell count of $1 \mathrm{x}$ $10^{6}$, each in a total volume of $250 \mu \mathrm{L}$ of PBS, followed by fixation and permeabilized using $250 \mu \mathrm{L}$ of Cytofix/ Cytoperm (BD Biosciences, San Diego, CA, USA) for 20 min at RT in the dark with gentle rocking. Cells were then washed in $1 \mathrm{~mL}$ of Perm/Wash buffer (BD Biosciences) and pelleted at $700 \mathrm{x}$ g for $10 \mathrm{~min}$ at RT. Cell pellets were resuspended in $150 \mu \mathrm{L}$ of PBS and incubated with $20 \mu \mathrm{L}$ of primary rabbit anti-MBP antibody (Millipore) for $60 \mathrm{~min}$ at RT. Stained cells were then washed once with the Perm/Wash buffer as described above, resuspended in $150 \mu \mathrm{L}$ of PBS, and stained further with $1 \mu \mathrm{L}$ ( $2 \mu \mathrm{g}$ of protein) of secondary antibody, goat anti-rabbit IgG-Alexa 488 (Invitrogen) for $30 \mathrm{~min}$ at RT in the dark. Cells were then washed with the Perm/Wash buffer and fixed using $300 \mu \mathrm{L}$ of $2 \%$ PFA.

For detection of oligodendrocyte apoptosis, cells were previously stained for MBP using primary and secondary antibody as described, and washed and pelleted using the Perm/Wash buffer. Cell pellets were then resuspended in $150 \mu \mathrm{L}$ of PBS and incubated for $1 \mathrm{~h}$ at RT with $20 \mu \mathrm{L}$ of phycoerythrin (PE)-conjugated anti-active caspase-3 antibody (BD), in the dark, for active caspase3 staining. Respective controls were included for cells without antibodies, single-stain controls for primary MBP antibody, secondary antibody anti-rabbit Alexa 
488, and PE-active-caspase-3 only, for compensation settings. Cells were then washed and pelleted as described above, and finally fixed using $300 \mu \mathrm{L}$ of $2 \%$ PFA and kept protected from light at $4^{\circ} \mathrm{C}$ until analyzed. As no nonspecific binding with isotype control for MBP was previously found in the immunofluorescence staining method described above, no isotype control was included here for flow cytometry evaluation.

Flow cytometric acquisition was performed within $24 \mathrm{~h}$ of staining. At least 100,000 events were collected from each sample using a FACS Calibur instrument (BD Biosciences). Data were analyzed using FlowJo software (TreeStar, Inc.) version 9.0.1.

\section{Statistical evaluation}

The unpaired-two tailed $t$ test was used to evaluate the statistical significance between means of datasets, using Graphpad Prizm software (Graph Pad Software Inc.) version 4.

\section{Results}

Expression of the mature oligodendrocyte marker MBP by differentiated MO3.13 cells and differentiated HOPC MO3.13 cell cultures held in growth medium expressed both MBP and GFAP (Figure 1A). Upon differentiation, mature MO3.13 oligodendrocytes showed elongated cell processes and continued to express MBP, while showing reduced GFAP expression as compared to undifferentiated cells (Figure 1B). Differentiated HOPC also expressed MBP (not shown in Figure 1, but see Figure 5 B-D). Oligodendrocytes incubated with respective isotype controls and corresponding secondary antibodies did not show any detectable signal (not shown).

\section{Pro-inflammatory response induced by $B$. burgdorferi in MO3.13 oligodendrocytes}

Live $B$. burgdorferi spirochetes incubated with differentiated MO3.13 cell cultures for $48 \mathrm{~h}$ at a MOI of 10:1 and 100:1 induced significantly elevated levels of CCL2 (Figure 2A), IL-6 (Figure 2B) and IL-8 (Figure 2C) as compared to the levels induced in medium controls. The concentration of CCL2 surpassed 8,000 pg/mL and $13,000 \mathrm{pg} / \mathrm{mL}$ at MOI of $10: 1$ and 100:1, respectively, whereas the constitutive level of this chemokine that was produced in medium alone was of $5,000 \mathrm{pg} / \mathrm{mL}$ (Figure 2A). The basal concentration of IL-6 was of only approximately $10 \mathrm{pg} / \mathrm{mL}$ but reached more than $130 \mathrm{pg} / \mathrm{mL}$ and $250 \mathrm{pg} / \mathrm{mL}$ at MOI of 10:1 and 100:1, respectively (Figure 2B). IL-8 production displayed a similar pattern but with higher values than IL-6 (Figure 2C). B. burgdorferi also induced marginally higher levels of the cytokines GMCSF and IFN- $\gamma$ in a dose-dependent manner as compared to controls (not shown). Data represent mean values and standard deviations between values of two independent experiments. The concentration values in each of the two experiments are the mean of duplicate determinations within the experiment.

\section{Evaluation of apoptosis of MO3.13 oligodendrocytes in the presence of $B$. burgdorferi}

Live $B$. burgdorferi induced apoptosis, as detected by the in situ TUNEL assay, in differentiated MO3.13

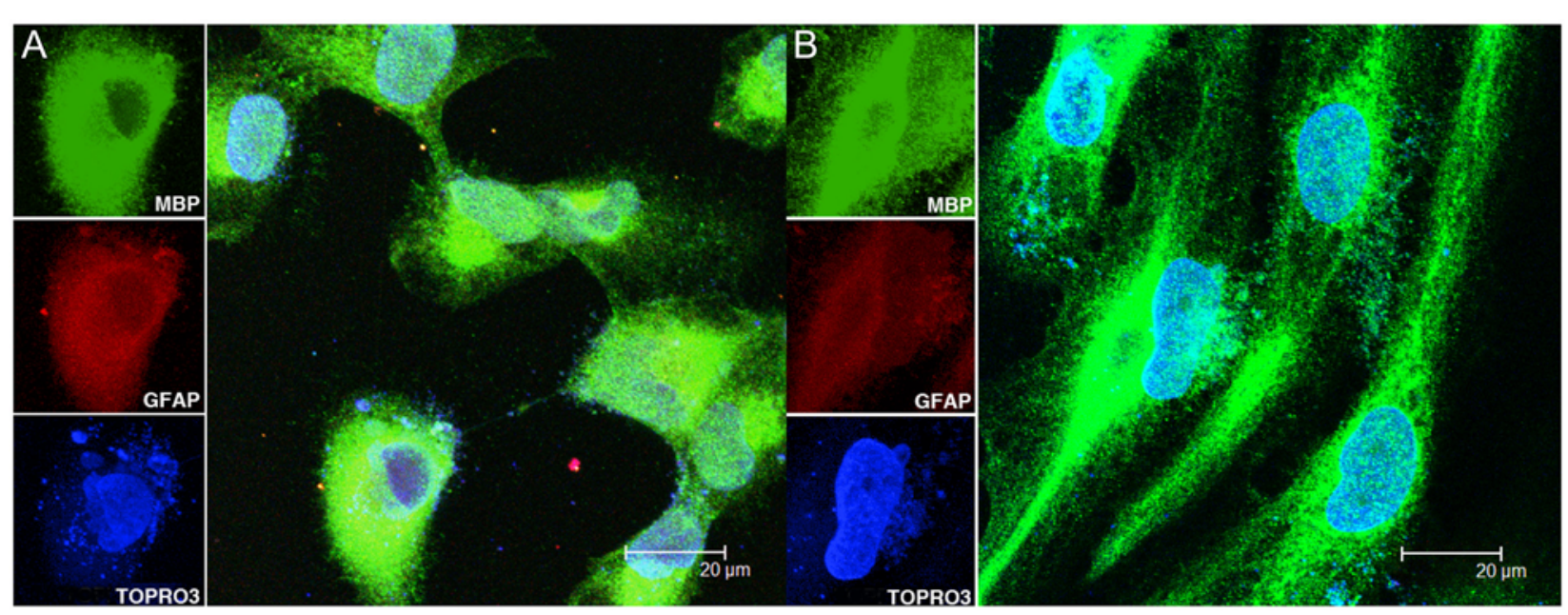

Figure 1 Cell morphology, myelin basic protein, and glial fibrillary acidic protein expression in MO3.13 oligodendrocyte cultures. MO3.13 cultures maintained in growth medium show expression of myelin basic protein (MBP, in green) and glial fibrillary acidic protein (GFAP red) (A). TOPRO3, a nuclear stain, appears blue. Upon differentiation, when growth medium is replaced with differentiation medium, cells change in morphology, continue to show expression of MBP, and the expression of GFAP is decreased (B). 


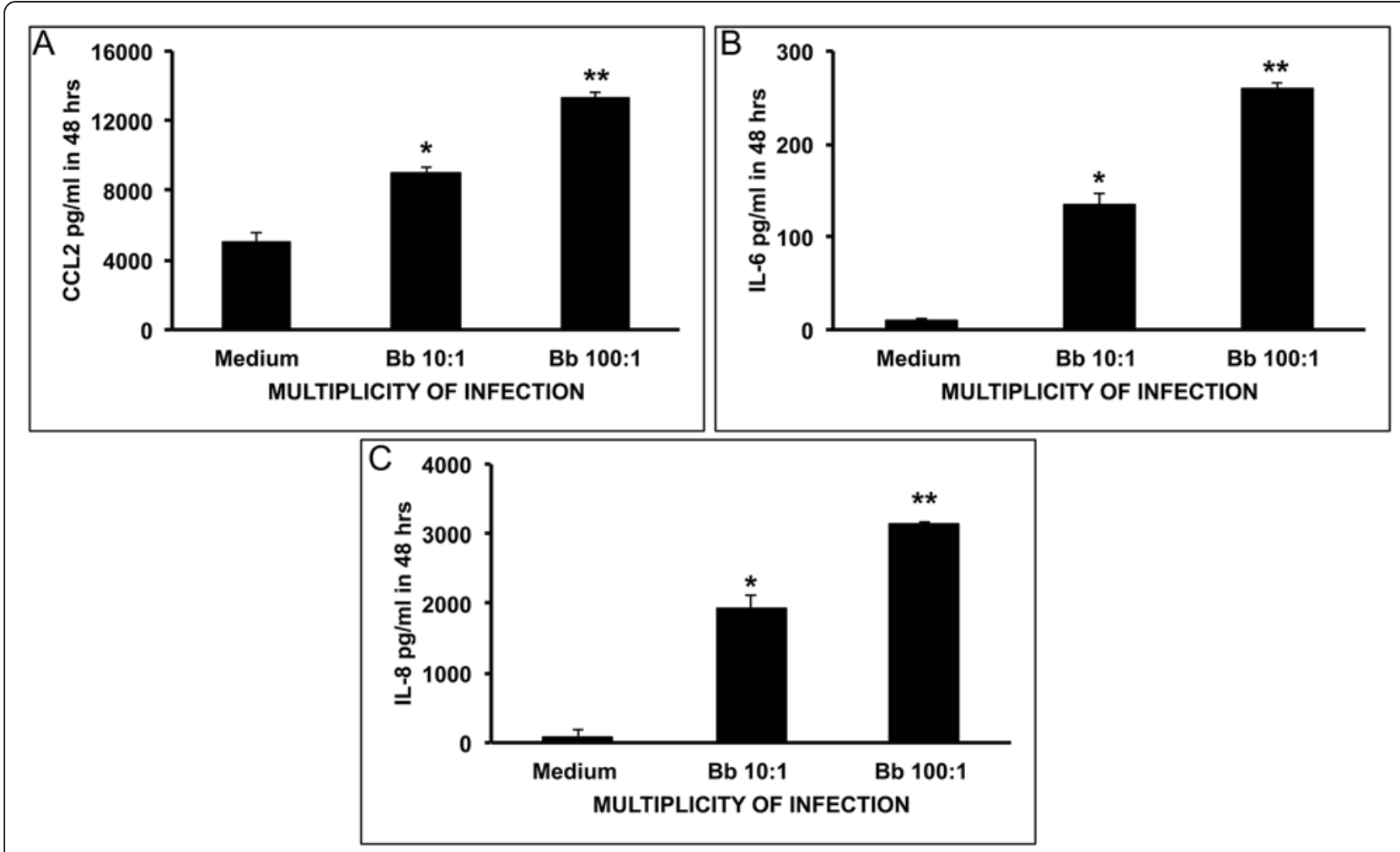

Figure 2 B. burgdorferi induces CCL2, IL-6 and IL-8 in MO3.13 oligodendrocytes in a dose dependent fashion. Evaluation by the multiplex ELISA assay of culture supernatants of differentiated $\mathrm{MO} 3.13$ oligodendrocytes incubated with live $B$. burgdorferi spirochetes at a multiplicity of infection (MOI) of 10:1, and 100:1 for 48 h show elevated levels of CCL2 (A), IL-6 (B), and IL-8 (C) as compared to that observed in medium controls (* $P<0.05$, ** $P<0.01$ ).

oligodendrocytes, after $48 \mathrm{~h}$ of incubation. Apoptosis visualized by confocal microscopy in medium alone, and after incubation with live B. burgdorferi at MOI of 10:1, 100:1, and 500:1 are shown in Figures 3 (A-D), respectively. The mean percent apoptosis and standard deviations quantified from ten microscope fields (a total of 500 cells) for each condition is shown in Figure 3E.

\section{Effect of the anti-inflammatory drug dexamethasone on the pro-inflammatory response elicited by $B$. burgdorferi in differentiated MO3.13 oligodendrocytes and differentiated HOPC}

Dexamethasone reduced the levels of CCL2, IL-6, and IL- 8 as induced by live $B$. burgdorferi (MOI of 10:1) in MO3.13 oligodendrocytes after $48 \mathrm{~h}$, as shown in Figures $4 \mathrm{~A}, 4 \mathrm{~B}$, and $4 \mathrm{C}$, respectively, in a dose-dependent fashion. Dexamethasone was able to significantly inhibit the levels of CCL2, IL-6, and IL-8 as induced by B. burgdorferi when used at $15 \mu \mathrm{M}$ and $150 \mu \mathrm{M}$ (Figure $4 \mathrm{~A}, \mathrm{~B}$, and $\mathrm{C}$ ). We confirmed that the anti-inflammatory effect of the dexamethasone formulation was due to its dexamethasone fraction and not due to the carrier substance (2-hydroxypropyl)- $\beta$-cyclodextrin (HPC), as HPC alone at $15 \mu \mathrm{M}, 45 \mu \mathrm{M}$, and $450 \mu \mathrm{M}$, the concentrations at which it is present in the dexamethasone concentrations used above, failed to reduce the levels of $B$. burgdorferi-induced immune mediators (Figure 4A, B, and C, respectively). Similarly, dexamethasone $(5 \mu \mathrm{M}, 15 \mu \mathrm{M}$, and $150 \mu \mathrm{M})$ reduced the levels of CCL 2 and IL- 8 as induced by live B. burgdorferi (MOI of 10:1) in HOPC cells after $48 \mathrm{~h}$ of co-incubation (Figure 4D and E).

\section{Effect of dexamethasone on apoptosis induced by $B$. burgdorferi in differentiated MO3.13 oligodendrocytes and differentiated HOPC}

Figure 5A shows percent apoptosis in MO3.13 oligodendrocytes as measured by the in situ TUNEL assay after $48 \mathrm{~h}$ of incubation in medium control $(2.85 \% \pm 0.91)$, with $B$. burgdorferi alone $(16 \% \pm 0.89)$ at MOI of $10: 1$, $B$. burgdorferi + dexamethasone as well as medium + dexamethasone at $5 \mu \mathrm{M}, 15 \mu \mathrm{M}$, and $150 \mu \mathrm{M}$. Dexamethasone was protective against $B$. burgdorferi-induced apoptosis, showing significant reduction in apoptosis at $15 \mu \mathrm{M}(8.93 \pm 0.65)$ and $150 \mu \mathrm{M}(7.6 \pm 0.99)(P<0.05)$. 

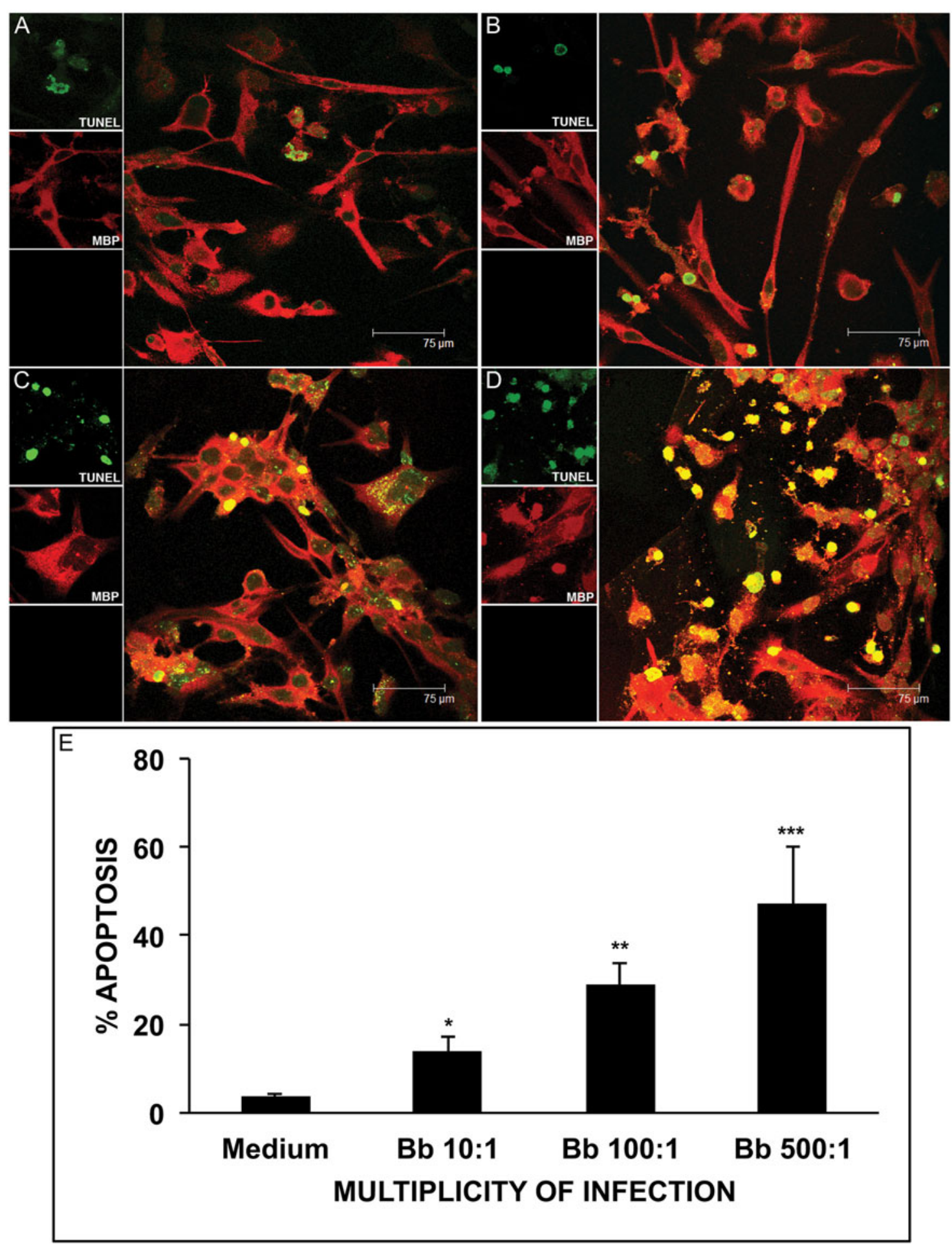

Figure 3 B. burgdorferi induces apoptosis in MO3.13 oligodendrocytes in a dose-dependent manner. Apoptosis detected by the in situ TUNEL assay (green) in MBP-stained differentiated MO3.13 cells (red), in medium control (A) and after incubation with live B. burgdorferi for $48 \mathrm{~h}$ at multiplicity of infection (MOI) of 10:1 (B), 100:1 (C), and 500:1 (D), as visualized by confocal microscopy. (E) : Graphical representation of the percent apoptosis as detected by the in situ TUNEL assay in differentiated MO3.13 cells held in medium control and after incubation with live $B$. burgdorferi at MOls of 10:1, 100:1, and 500:1, respectively, for $48 \mathrm{~h}\left({ }^{*} P<0.05\right.$, ${ }^{* *} P<0.01$, $\left.{ }^{* * *} P<0.001\right)$. 


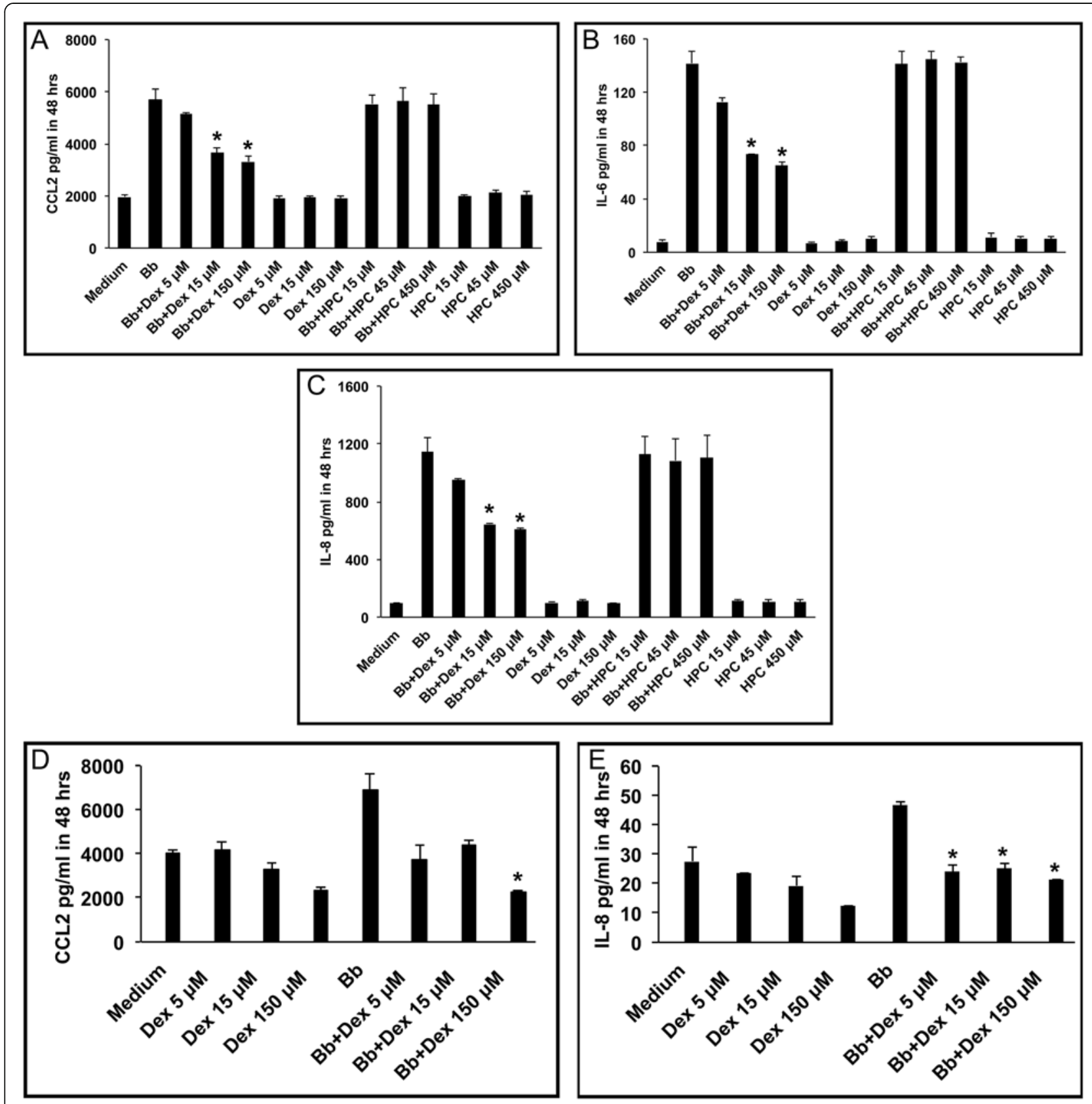

Figure 4 Dexamethasone reduces levels of CCL2, IL-6, and IL-8 induced by B. burgdorferi in differentiated oligodendrocytes. Evaluation by the multiplex ELISA assay of culture supernatants of differentiated MO3.13 oligodendrocytes incubated with live B. burgdorferi spirochetes at a multiplicity of infection (MOI) of 10:1 for $48 \mathrm{~h}$ in the presence and absence of dexamethasone (Dex) at $5 \mu \mathrm{M}, 15 \mu \mathrm{M}$, and $150 \mu \mathrm{M}$ concentrations and carrier substance (2-hydroxypropyl)- $\beta$-cyclodextrin (HPC), at $15 \mu \mathrm{M}, 45 \mu \mathrm{M}$, and $450 \mu \mathrm{M}$, respectively, showing levels of CCL2 (A), IL-6 (B), and IL-8 (C). Levels of CCL2 (D) and IL-8 (E) detected in culture supernatants of differentiated primary human oligodendrocytes, as induced by live $B$. burgdorferi after $48 \mathrm{~h}$ of incubation in the presence and absence of dexamethasone at $5 \mu \mathrm{M}, 15 \mu \mathrm{M}$, and $150 \mu \mathrm{M}$ concentrations ( ${ }^{*} P<0.05$ ).

However, when dexamethasone was used at the high concentration of $1,500 \mu \mathrm{M}$ it appeared to be toxic, as it not only resulted in higher levels of apoptosis than that induced by $B$. burgdorferi alone $(84.4 \% \pm 1.2)$, but it also induced high levels of apoptosis in cells incubated in medium alone (75.8\%) (not shown in Figure 5A).

Live B. burgdorferi also induced enhanced apoptosis as evaluated by the in situ TUNEL assay and visualized by 

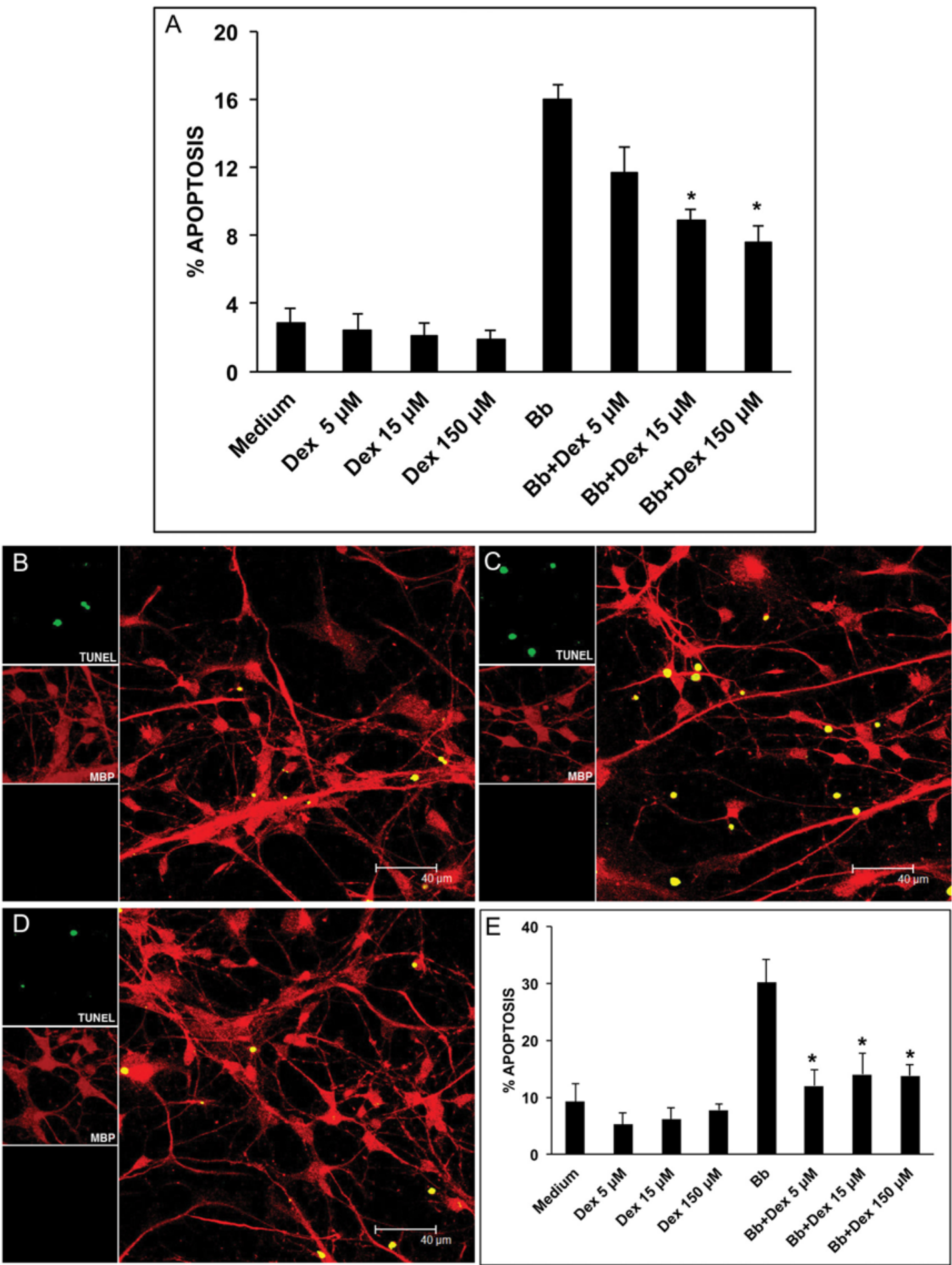

Figure 5 Dexamethasone protects differentiated human oligodendrocytes from $B$. burgdorferi-induced apoptosis in a dose dependent fashion. A graphical representation of the percent apoptosis as evaluated by the in situ TUNEL assay in differentiated MO3.13 oligodendrocytes (A) in the presence and absence of dexamethasone (Dex) at $5 \mu \mathrm{M}, 15 \mu \mathrm{M}$, and $150 \mu \mathrm{M}$ concentrations. Confocal images showing apoptosis as observed by the in situ TUNEL assay in differentiated human oligodendrocyte precursor cells (HOPC) incubated for $48 \mathrm{~h}$ in medium (B), B. burgdorferi at $\mathrm{MOI}$ of 10:1 (C) and B. burgdorferi (10:1) in the presence of dexamethasone at $5 \mu \mathrm{M}(\mathbf{D})$. The TUNEL signal is seen in green in differentiated HOPC showing expression of myelin basic protein (MBP), in red. (E) Graphical representation of the protective effect of dexamethasone on B. burgdorferi-induced apoptosis in HOPC at $5 \mu \mathrm{M}, 15 \mu \mathrm{M}$, and $150 \mu \mathrm{M}$ concentrations, $\left(^{*} P<0.05\right)$. 
confocal microscopy in differentiated HOPC cells, Figure $5 \mathrm{C}$, as compared to that seen in medium controls, Figure $5 \mathrm{~B}$, after $48 \mathrm{~h}$ of incubation. A confocal image of the protective effect of dexamethasone at $5 \mu \mathrm{M}$ on B. burgdorferi-induced apoptosis is shown in Figure 5D. Figure 5E shows a graph of the percent apoptosis observed in HOPC cells when incubated with live B. burgdorferi, and medium controls in the presence and absence of dexamethasone at 5 $\mu \mathrm{M}, 15 \mu \mathrm{M}$, and $150 \mu \mathrm{M}$ after $48 \mathrm{~h}$ of incubation. Dexamethasone significantly reduced the levels of B. burgdorferiinduced apoptosis in HOPC cells from $(30.19 \% \pm 4.12)$ to $12.05 \% \pm 2.8$ in the presence of $5 \mu \mathrm{M}$ dexamethasone,
$14.05 \% \pm 3.58$ at $15 \mu \mathrm{M}$, and $13.79 \% \pm 2$ at $150 \mu \mathrm{M}$, respectively $(P<0.05)$.

\section{Caspase-3 activation induced by $B$. burgdorferi in differentiated MO3.13 oligodendrocytes}

Caspase- 3 activation was quantified by flow cytometry in differentiated MO3.13 cells in the presence and absence of live B. burgdorferi (Figure 6). Cells were incubated with spirochetes for $48 \mathrm{~h}$. The percent of MBP-positive cells showing positive staining for activated caspase- 3 in cultures held in medium $(0.18 \pm 0.1)$ was elevated by 30 fold in MO3.13 cells incubated with live B. burgdorferi

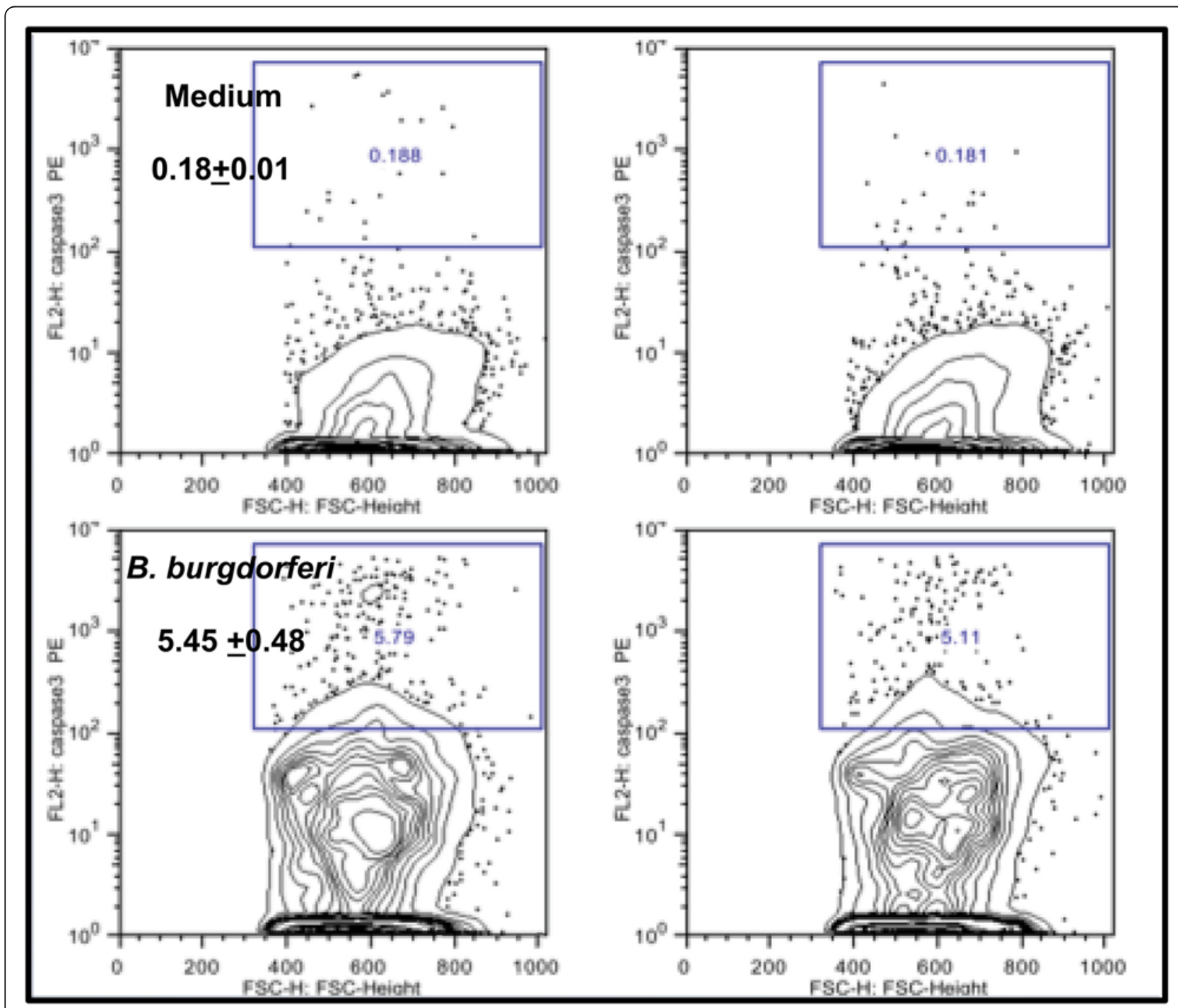

Figure 6 B. burgdorferi induces elevated levels of activated caspase-3 in differentiated MO3.13 cells. Flow cytometric evaluation of activated caspase-3 in differentiated MO3.13 cells following incubation in differentiation medium (top panel) and with live B. burgdorferi (MOI, 10:1) for $48 \mathrm{~h}$ (bottom panel). The mean percent of MBP-positive cells showing positive staining for activated caspase-3 in cultures held in medium $(0.18 \pm 0.1)$ was elevated by 30 -fold in MO3.13 cells incubated with live $B$. burgdorferi $(5.45 \pm 0.48)$. The figure shows the results of two independent experiments. 
$(5.45 \pm 0.48)$. The results represent the mean and standard deviation of values obtained from two independent experiments.

\section{Discussion}

In recent studies, using ex vivo and in vivo modes of experimentation in the rhesus monkey model of LNB, we had established that $B$. burgdorferi is able to induce inflammatory mediators, with concomitant apoptosis of oligodendrocytes in the frontal cortex, and of satellite glial cells in dorsal root ganglia $[39,40]$. We had also shown with experiments performed in vitro that human neurons co-cultured with $B$. burgdorferi and rhesus microglia undergo apoptosis in the presence of pro-inflammatory mediators chiefly produced by the microglia [44]. In this study we focused on evaluating the ability of live $B$. burgdorferi to induce oligodendrocyte damage in an in vitro system, using differentiated MO3.13 human oligodendrocytes and differentiated HOPC. We addressed the hypothesis that inflammation plays a role in mediating apoptosis of oligodendrocytes, as induced by $B$. burgdorferi, using the anti-inflammatory drug dexamethasone. We included HOPC in our study to corroborate the observations that we made with the MO3.13 cell line.

We established in vitro cultures of MO3.13 cells and confirmed the presence of phenotypic markers that are known to be expressed by this cell line, namely MBP and GFAP [41].

Our first key observation was that B. burgdorferi is able to induce the pro-inflammatory mediators CCL2, IL-6, and IL-8 in oligodendrocytes. The levels of immune mediators detected in the culture supernatants increased concordantly with an increase in the spirochetal MOI. HOPC similarly produced CCL2 and IL-8, a finding that further validates the results obtained with MO3.13 cells. These observations echo our previous findings made with astrocytes and microglia, as these glial cells also produced pro-inflammatory mediators in response to live $B$. burgdorferi, and expand the scope of our hypothesis of a role for glial cells in mediating inflammation in LNB [39,40,44-46]. Oligodendrocytes could therefore contribute to the elevated levels of cytokines and chemokines detected in the CSF of patients with LNB [35-38].

Cytokines and chemokines play a central role in inflammation, demyelination, and neurodegeneration in the CNS during inflammatory neurodegenerative diseases such as multiple sclerosis (MS) [47]. Oligodendrocytes in brain tissue that is immediately adjacent to the subarachnoid space, the region known as the sub-pial space, are especially vulnerable to demyelination [48]. Since inflammatory lesions are commonly found in the meninges in LNB, the myelitis that is seen in LNB may be in part due to oligodendrocytes. These cells could be damaged by the inflammatory process brought about by the oligodendrocytes themselves, with participation of other glial cells, in addition to inflammatory mediators produced by the perivascular cellular infiltrates that are often present in CNS infection. Oligodendrocytes are known to express receptors for various cytokines and chemokines [49].

CCL2 was induced at high levels in oligodendrocytes by B. burgdorferi. This chemokine is of particular importance in mediating inflammation in neurodegenerative diseases [50]. CCL2 recruits monocytes and T cells from the blood stream into the CNS during acute neuroinflammation, in addition to recruiting microglia, the resident macrophages of the brain [51]. It is an important mediator in many neuroinflammatory and neurodegenerative brain diseases characterized by neuronal degeneration [52]. CCL2 has been found to be up-regulated in actively demyelinating MS plaques [53], and its expression is increased in experimental autoimmune encephalomyelitis [54]. It is known to modulate microglial activation and proliferation, thus contributing to the inflammatory response mounted by the CNS [55]. Importantly, CCL2 levels are elevated in the CSF of patients with LNB [56], and we found high levels of CCL2 in the CSF of rhesus monkeys infected intrathecally with $B$. burgdorferi [40]. CCL2 also has been documented to play a role in mediating nerve damage and demyelination of axons by causing influx of monocytes and T cells, in Wallerian degeneration $[57,58]$, and may thus contribute to the axonal damage that affects patients with LNB of the PNS $[10,11]$.

The cytokine IL-6, which was also elevated in the culture supernatants of oligodendrocytes that were exposed to live B. burgdorferi, is known to be both helpful and harmful in the CNS [31-34]. Dysregulated expression of IL-6 has been documented in several neurological disorders such as MS, acute transverse myelitis, Alzheimer's disease, schizophrenia, epileptic seizures, and Parkinson's disease [49]. In addition, IL-6 has been shown to be involved in multiple physiological CNS processes such as neuron homeostasis, astrogliogenesis, and neuronal differentiation [59]. Elevated levels of IL-6 have also been found in the CSF of LNB patients [35]. IL-6 is known to promote oligodendrocyte and neuronal survival in the presence of glutamate-mediated excitotoxicity in hyppocampal slices [60]. IL-6 is also known to support survival of oligodendrocytes in vitro [61].

The third pro-inflammatory mediator whose concentration was significantly increased in culture supernatants of oligodendrocytes stimulated with live $B$. burgdorferi is IL-8. This chemokine also has been reported to be elevated in the CSF of LNB patients [62]. We had previously documented that B. burgdorferi induces production of IL-8 in rhesus microglia, astrocytes and endothelial cells [39,40,44,46]. IL-8 released into the CSF after brain injury is associated with bloodbrain barrier dysfunction and plays a central role in 
recruitment of neutrophils and $\mathrm{T}$ cells into the CNS during bacterial meningitis $[63,64]$.

Our second key observation was that live B. burgdorferi induce a significantly elevated level of apoptosis, as assessed by the TUNEL assay, in MO3.13 oligodendrocytes compared to that seen in medium controls. The level of apoptosis observed increased concordantly with an increase in the B. burgdorferi MOI. We also observed elevated levels of activated caspase-3, a phenomenon that is known to be an early signaling event that results in apoptosis [65]. The MO3.13 oligodendrocyte cell line used in these studies has also been shown to undergo active caspase-3-mediated apoptosis due to other stimuli such as ceramide $[66,67]$, and inflammatory cytokines [68]. Caspase- $1,-2$ and -3 are known to be expressed in mature oligodendrocytes [69]. Caspase-mediated oligodendrocyte cell death (particularly via activation of caspase-11 and caspase-3) has also been documented in inflammatory demyelinating diseases such as MS [70].

The interaction of B. burgdorferi with oligodendrocytes resulted in elevated levels of inflammatory mediators and concomitant apoptosis in oligodendrocytes, suggesting that the phenomena of inflammation and apoptosis might be causally related. To uncover the possible connection between inflammation and apoptosis in this system we treated both differentiated MO3.13 cells as well as differentiated HOPC with the anti-inflammatory drug dexamethasone. In both cases the effect was not only a reduction in the amount of pro-inflammatory mediators, as would be expected in the presence of dexamethasone, but also a significant reduction in the fraction of cells undergoing apoptosis. This outcome is a strong indication that inflammation plays a role in mediating oligodendrocyte apoptosis.

Cytokines such as TNF, IL-1 $\beta$, lymphotoxin (LT), and TGF- $\beta$ are known to cause cell death in oligodendrocytes [71-74]. TNF and IL-1 $\beta$ were not detected in the culture supernatants of oligodendrocytes that were incubated with live $B$. burgdorferi for $48 \mathrm{~h}$. TGF- $\beta$ and LT were not among the mediators that were detected by the human 14-plex array that we used and may well have been present in the culture supernatants. TNF, LT, [71] and TGF- $\beta$ [72] were shown to induce apoptosis in oligodendrocytes when added exogenously, while IL-1 $\beta$ caused glutamate-mediated excitotoxic death of oligodendrocytes co-cultured with astrocytes and microglia [73], or when injected intra-cerebrally in neonatal rats [74].

The potential of CCL2, IL-6, and/or IL-8 to induce oligodendrocyte apoptosis has not been documented thus far in the literature. In fact, IL-6 is known to promote the survival of oligodendrocytes in culture [61]. IL-8 has been shown to induce the expression of pro-inflammatory proteases, matrix metalloproteinases MMP-2 and MMP-9, cell-cycle protein cyclin D1, an early marker for G1/S transition and pro-apoptotic protein Bim (Bcl-2-interacting mediator of cell death), and cell death in cultured neurons in $24 \mathrm{~h}$ [75]. CCL2 is implicated in mediating oligodendrocyte/white matter damage indirectly by mediating the influx of immune cells such as $\mathrm{T}$ cells and macrophages, resulting in cytotoxic damage of the myelin sheath of axons, followed by phagocytosis of myelin debris, culminating in demyelination and axonal damage [76]. A possible involvement of cytotoxic cells in the immune response against $B$. burgdorferi has been suggested based on in vitro studies [77], in addition to reports indicating the presence of a cytolytic phenotype of IFN- $\gamma$ producing cells from patients with LNB [78]. It is likely that a similar mechanism may be mediating the demyelination and axonal degeneration resulting in white matter lesions seen in LNB $[4,6,18-22]$.

The anti-inflammatory effect of dexamethasone, a glucocorticoid used in the treatment of immunemediated inflammatory diseases is well documented [42]. Dexamethasone has been shown to effectively reduce the levels of IL- 6 , IL-1 $\beta$, and TNF released from human monocytes stimulated with endotoxin to below background levels [79]. Dexamethasone reduced the levels of CCL2 in brain and retinal vascular endothelial cells that were activated with pro-inflammatory cytokines IL-1 $\beta$, TNF, and IFN- $\gamma$ [80]. The anti-inflammatory potential of dexamethasone to reduce CCL2 and IL-8 also has been reported in cultured rheumatoid synoviocytes [81]. Here we show that dexamethasone can reduce the levels of CCL2, IL- 6 , and IL- 8 as induced by $B$. burgdorferi in differentiated human oligodendrocytes. Clinical improvement was seen in a severe case of neuroborreliosis showing encephalomyelitis with polyneuropathy, when treated with the classically recommended 2 to 4 weeks of anti-microbial agents in combination with steroids [82].

Dexamethasone has been shown to suppress CCL2 production via mitogen-activated protein kinase phosphatase-1 (MAPK-P1)-dependent inhibition of Jun N-terminal kinase and p38 MAPK in activated rat microglia [43]. MAPK cascades are signal transduction pathways that play important regulatory roles in the biosynthesis of pro-inflammatory cytokines such as IL-6, IL-8, and CCL2 [83]. MAKP-P1, a member of the Map Kinase Phosphatase family, is essential for the dephosphorylation/deactivation of MAPK p38 and JNK, thereby limiting pro-inflammatory cytokine biosynthesis in innate immune cells exposed to microbial components or infectious agents [84]. MAPK such as p38 and JNK may be involved in the signaling mechanisms underlying both inflammation and apoptosis [83,85]. Earlier we had documented the role of p38 MAPK, Erk1, and Erk 2 in mediating the production of IL- 6 and TNF, as well as apoptosis, in rhesus astrocytes as induced by lipoproteins of $B$. burgdorferi [86]. MAPK signaling pathways may indeed be 
involved in regulating both inflammation and apoptosis as induced by $B$. burgdorferi in human oligodendrocytes, as well as in the modulatory effect of dexamethasone that we observed.

\section{Conclusions}

In this study we have established that live B. burgdorferi are capable of eliciting inflammatory mediators, particularly IL-6, IL-8, and CCL2, in addition to inducing apoptosis in human oligodendrocyte cultures in vitro, by activating caspase-3. Oligodendrocytes are the myelinating cells of the CNS that myelinate neuronal axons, providing saltatory conduction of action potentials and proper function of the CNS [87]. The role of oligodendrocyte death in MS is well established [88]. Some of the earliest pathological changes in inflammatory lesions seen in MS are increases in oligodendrocyte apoptosis [89,90]. Based on the observations of this study we propose that neurologic injury in the CNS during an infection with the Lyme disease spirochete B. burgdorferi could be mediated in part by the direct action of the spirochetes on oligodendrocytes or via inflammation mediated by $B$. burgdorferi in oligodendrocytes. As oligodendrocytes are vital for the survival and optimum function of neurons [91], oligodendrocyte damage could contribute to neuronal dysfunction and death and result in the impairment of CNS functions that are seen in patients with LNB.

\section{Competing interests}

The authors declare that they have no competing interests.

\section{Acknowledgments}

This project was supported by the National Institute of Neurologic Disorders and Stroke through grant number NS048952, and by the National Center for Research Resources and the Office of Research Infrastructure Programs (ORIP) of the National Institutes of Health through grant number OD011104-51. Robin Rodriguez is gratefully acknowledged for help with formatting the figures.

\section{Author details}

${ }^{1}$ Division of Bacteriology and Parasitology, Tulane National Primate Research Center, Covington, LA, USA. ${ }^{2}$ School of Science and Engineering, Tulane University, New Orleans, LA, USA. ${ }^{3}$ Division of Comparative Pathology, Tulane National Primate Research Center, Covington, LA, USA.

\section{Authors' contributions}

GR participated in the design of the experiments, conducted cell culture experiments, multiplex ELISA data analysis, confocal microscopy, preparation and staining of samples for flow cytometry, and drafted the manuscript. SB helped in cell culture, immunofluorescence, and multiplex ELISA data analysis. BP performed the flow cytometry experiments. MP conceived of the study, contributed to the design of the experiments, and to drafting and editing the manuscript. All authors have read and approved the final version of the manuscript.

Received: 10 February 2012 Accepted: 13 March 2012 Published: 23 April 2012

\section{References}

1. Halperin JJ: Nervous system Lyme disease. J R Coll Physicians Edinb 2010, 40:248-255.

2. Fallon BA, Levin ES, Schweitzer PJ, Hardesty D: Inflammation and central nervous system Lyme disease. Neurobiol Dis 2010, 37:534-541.
3. Reik L, Steere AC, Bartenhagen NH, Shope RE, Malawista SE: Neurologic abnormalities of Lyme disease. Medicine (Baltimore) 1979, 58:281-294.

4. Halperin JJ, Volkman DJ, Wu P: Central nervous system abnormalities in Lyme neuroborreliosis. Neurology 1991, 41:1571-1582.

5. Neophytides A, Khan S, Louie E: Subacute cerebellitis in Lyme disease. Int J Clin Pract 1997, 51:523-524.

6. Kohler J: Lyme borreliosis: a case of transverse myelitis with syrinx cavity. Neurology 1989, 39:1553-1554.

7. Meurs L, Labeye D, Declercq I, Piéret F, Gille M: Acute transverse myelitis as a main manifestation of early stage II neuroborreliosis in two patients. Eur Neurol 2004, 52:186-188.

8. Koc F, Bozdemir H, Pekoz T, Aksu HS, Ozcan S, Kurdak H: Lyme disease presenting as subacute transverse myelitis. Acta Neurol Belg 2009, 109:326-329.

9. Bigi S, Aebi C, Nauer C, Bigler S, Steinlin M: Acute transverse myelitis in Lyme neuroborreliosis. Infection 2010, 38:413-416.

10. Componovo F, Meier C: Neuropathy of vasculitic origin in a case of GarinBoujadoux-Bannwarth syndrome with positive borrelia antibody response. J Neurol 1986, 233:69-72.

11. Kindstrand E, Nilsson BY, Hovmark A, Nennesmo I, Pirskanen R, Solders G, Asbrink E: Polyneuropathy in late Lyme borreliosis - a clinical, neurophysiological and morphological description. Acta Neurol Scand 2000, 101:47-52.

12. Lana-Peixoto MA: Multiple sclerosis and positive Lyme serology. Arq Neuropsiquiatr 1994, 52:566-571.

13. Brinar W, Habek M: Rare infections mimicking MS. Clin Neurol Neurosurg 2010, 112:625-628.

14. Pachner AR: Borrelia burgdorferi in the nervous system: the new "great imitator". Ann N Y Acad Sci 1988, 539:56-64.

15. Hildenbrand $P, C$ raven $D E$, Jones $R$, Nemeskal P: Lyme neuroborreliosis: manifestations of a rapidly emerging zoonosis. AJNR Am J Neuroradiol 2009, 30:1079-1087.

16. Martin R, Gran B, Zhao Y, Markovic-Plese S, Bielekova B, Marques A, Sung $\mathrm{MH}$, Hemmer B, Simon R, McFarland HF, Pinilla C: Molecular mimicry and antigen-specific $T$ cell responses in multiple sclerosis and chronic CNS Lyme disease. J Autoimmun 2001, 16:187-192.

17. Fritzsche M: Chronic Lyme borreliosis at the root of multiple sclerosis: is a cure with antibiotics attainable?. Med Hypotheses 2005, 64:438-448.

18. Halperin JJ: Neuroborreliosis: central nervous system involvement. Semin Neurol 1997, 17:19-24.

19. Steinbach JP, Melms A, Skalej M, Dichgans J: Delayed resolution of white matter changes following therapy of $B$. burgdorferi encephalitis. Neurology 2005, 64:758-759.

20. Benach JL: Borrelia burgdorferi in the central nervous system. JAMA 1992 268:872. author reply 873 .

21. Oksi J, Kalimo H, Marttila RJ, Marjamäki M, Sonninen P, Nikoskelainen J, Viljanen MK: Inflammatory brain changes in Lyme borreliosis. A report on three patients and review of literature. Brain 1996, 119:2143-2154.

22. Dryden MS, O'Connell S, Samuel W, lannotti F: Lyme myelitis mimicking neurological malignancy. Lancet 1996, 348:624.

23. Suchanek G, Kristoferitsch W, Stanek G, Bernheimer H: Anti-myelin antibodies in cerebrospinal fluid and serum of proteins with meningopolyneuritis Garin-Bujadoux-Bannwarth and other neurological diseases. Zentralbl Bakteriol Mikrobiol Hyg A 1986, 263:160-168.

24. Baig S, Olsson T, Höjeberg B, Link H: Cells secreting antibodies to myelin basic protein in cerebrospinal fluid of patients with Lyme neuroborreliosis. Neurology 1991, 41:581-587.

25. Dotevall L, Hagberg L, Karlsson JE, Rosengren LE: Astroglial and neuronal proteins in cerebrospinal fluid as markers of CNS involvement in Lyme neuroborreliosis. Eur J Neurol 1999, 6:169-178.

26. Garcia-Moncó JC, Benach JL: Mechanisms of injury in Lyme neuroborreliosis. Semin Neurol 1997, 17:57-62.

27. Livengood JA, Gilmore RD Jr: Invasion of human neuronal and glial cells by an infectious strain of Borrelia burgdorferi. Microbes Infect 2006, 8:2832-2840.

28. García-Moncó JC, Fernández-Villar B, Benach JL: Adherence of the Lyme disease spirochete to glial cells and cells of glial origin. J Infect Dis 1989, 160:497-506.

29. Garcia-Moncó JC, Fernández-Villar B, Szczepanski A, Benach JL: Cytotoxicity of Borrelia burgdorferi for cultured rat glial cells. J Infect Dis 1991, 163:1362-1366.

30. Benveniste EN: Inflammatory cytokines within the central nervous system: sources, function, and mechanism of action. Am J Physiol 1992, 263:C1-C16. 
31. Merrill JE, Benveniste EN: Cytokines in inflammatory brain lesions: helpful and harmful. Trends Neurosci 1996, 19:331-338.

32. Rothwell NJ, Strijbos PJ: Cytokines in neurodegeneration and repair. Int $J$ Dev Neurosci 1995, 13:179-185.

33. Raivich G, Jones LL, Werner A, Blüthmann H, Doetschmann T, Kreutzberg GW Molecular signals for glial activation: pro-and anti-inflammatory cytokines in the injured brain. Acta Neurochir Suppl 1999, 73:21-30.

34. Minghetti $L$ : Role of inflammation in neurodegenerative diseases. Curr Opin Neurol 2005, 18:315-321.

35. Weller M, Stevens A, Sommer N, Wiethölter H, Dichgans J: Cerebrospinal fluid interleukins, immunoglobulins, and fibronectin in neuroborreliosis. Arch Neurol 1991, 48:837-841.

36. Grusell M, Widhe M, Ekerfelt C: Increased expression of the Th1-inducing cytokines interleukin-12 and interleukin-18 in cerebrospinal fluid but not in sera from patients with Lyme neuroborreliosis. J Neuroimmunol 2002, 131:173-178.

37. Widhe $M$, Jarefors S, Ekerfelt C, Vrethem M, Bergstrom S, Forsberg $P$ Ernerudh J: Borrelia-specific interferon-gamma and interleukin-4 secretion in cerebrospinal fluid and blood during Lyme borreliosis in humans: association with clinical outcome. J Infect Dis 2004, 189:1881-1891.

38. Widhe M, Skogman BH, Jarefors $S$, Eknefelt M, Eneström G, Nordwall M, Ekerfelt C, Croner S, Bergström S, Forsberg P, Ernerudh J: Up-regulation of Borreliaspecific IL-4 and IFN-gamma-secreting cells in cerebrospinal fluid from children with Lyme neuroborreliosis. Int Immuno/ 2005, 17:1283-1291.

39. Ramesh G, Borda JT, Dufour J, Kaushal D, Ramamoorthy R, Lackner AA, Philipp MT: Interaction of the Lyme disease spirochete Borrelia burgdorferi with brain parenchyma elicits inflammatory mediators from glial cells as well as glial and neuronal apoptosis. Am J Pathol 2008, 173:1415-1427.

40. Ramesh G, Borda JT, Gill A, Ribka EP, Morici LA, Mottram P, Martin DS, Jacobs MB, Didier PJ, Philipp MT: Possible role of glial cells in the onset and progression of Lyme neuroborreliosis. J Neuroinflammation 2009, 6:23-38.

41. McLaurin J, Trudel GC, Shaw IT, Antel JP, Cashman NR: A human glial hybrid cell line differentially expressing genes subserving oligodendrocyte and astrocyte phenotype. J Neurobiol 1995, 26:283-293.

42. Abraham SM, Lawrence T, Kleiman A, Warden P, Medghalchi M, Tuckermann J, Saklatvala J, Clark AR: Anti-inflammatory effects of dexamethasone are partly dependent on induction of dual specificity phosphatase 1. J Exp Med 2006, 203:1883-1889.

43. Zhou Y, Ling EA, Dheen ST: Dexamethasone suppresses monocyte chemoattractant protein-1 production via mitogen activated protein kinase phosphatase- 1 dependent inhibition of Jun $\mathrm{N}$-terminal kinase and p38 mitogen-activated protein kinase in activated microglia. J Neurochem 2007, 102:667-678.

44. Myers TA, Kaushal D, Philipp MT: Microglia are mediators of Borrelia burgdorferi-induced apoptosis in SH-SY5Y neuronal cells. PLOS Pathog 2009, 5:e1000659.

45. Ramesh G, Alvarez AL, Roberts ED, Dennis VA, Lasater BL, Alvarez X, Philipp MT: Pathogenesis of Lyme neuroborreliosis: Borrelia burgdorferi lipoproteins induce both proliferation and apoptosis in rhesus monkey astrocytes. Eur J Immunol 2003, 33:2539-2550.

46. Bernardino AL, Myers TA, Alvarez X, Hasegawa A, Philipp MT: Toll-like receptors: insights into their possible role in the pathogenesis of Lyme neuroborreliosis. Infect Immun 2008, 76:4385-4395.

47. Stadelmann C, Wegner C, Brück W: Inflammation, demyelination and degeneration-recent insights from MS pathology. Biochim Biophys Acta 2011, 1812:275-282.

48. $B \varnothing L$, Vedeler CA, Nyland HI, Trapp BD, Mørk SJ: Subpial demyelination in the cerebral cortex of multiple sclerosis patients. J Neuropathol Exp Neurol 2003, 62:723-732.

49. Schmitz $T$, Chew $\sqcup$ : Cytokines and myelination in the central nervous system. Sci World J 2008, 8:1119-1147.

50. Conductier G, Blondeau N, Guyon A, Nahon JL, Rovère C: The role of monocyte chemoattractant protein MCP1/CCL2 in neuroinflammatory diseases. J Neuroimmunol 2010, 224:93-100

51. Rollins BJ: Monocyte chemoattractant protein-1: a potential regulator of monocyte recruitment in inflammatory disease. Mol Med Today 1996, 2:198-204.

52. Gerard C, Rollins BJ: Chemokines and disease. Nat Immuno/ 2001, 2:108-115.

53. Simpson JE, Newcombe J, Cuzner ML, Woodroofe MN: Expression of monocyte chemoattractant protein- 1 and other beta-chemokines by resident glia and inflammatory cells in multiple sclerosis lesions. J Neuroimmunol 1998, 84:238-249.

54. Ransohoff RM, Hamilton TA, Tani M, Stoler MH, Shick HE, Major JA, Estes ML, Thomas DM, Tuohy VK: Astrocyte expression of mRNA encoding cytokines IP-10 and JE/MCP-1 in experimental autoimmune encephalomyelitis. FASEB 1993, 7:592-600.

55. Hinojosa AE, Garcia-Bueno B, Leza JC, Madrigal JL: CCL2/MCP-1 modulation of microglial activation and proliferation. J Neuroinflammation 2011, 8:77-86.

56. Grygorczuk S, Zajkowska J, Swierzbińska R, Pancewicz S, Kondrusik M, Hermanowska-Szpakowicz T: Concentration of interferon-inducible T cell chemoattractant and monocyte chemotactic protein-1 in serum and cerebrospinal fluid patients with Lyme borrreliosis. Rocz Akad Med Bialymst 2005, 50:173-178.

57. Perrin FE, Lacroix S, Avilés-Trigueros M, David S: Involvement of monocyte chemoattractant protein-1, macrophage inflammatory protein-1 alpha and interleukin-1 beta in Wallerian degeneration. Brain 2005, 128:854-866.

58. Rotshenker S: Wallerian degeneration: the innate-immune response to traumatic nerve injury. J Neuroinflammation 2011, 8:109.

59. Spooren A, Kolmus K, Laureys G, Clinkers R, De Keyser J, Haegeman G, Gerlo S: Brain Interleukin-6, a mental cytokine. Res Rev 2011, 67:157-183.

60. Pizzi M, Sarnico I, Boroni F, Benarese M, Dreano M, Garotta G, Valerio A, Spano P: Prevention of neuron and oligodendrocyte degeneration by interleukin-6 (IL-6) and IL-6 receptor/IL-6 fusion protein in organotypic hippocampal slices. Mol Cell Neuroscienci 2004, 25:301-311.

61. Barres BA, Schmid R, Sendnter M, Raff MC: Multiple extracellular signals are required for long-term oligodendrocyte survival. Development 1993, 118:283-295.

62. Grygorczuk S, Pancewicz S, Zajkowska J, Kondrusik M, Rwierzbińska R, Kermanowska-Szpakowicz T: Concentrations of macrophage inflammatory proteins MIP-1alpha and MIP-1beta and interleukin 8 (IL-8) in Lyme borreliosis. Infection 2004, 32:350-355.

63. Kossmann T, Stahel PF, Lenzlinger PM, Redl H, Dubs RW, Trentz O, Schlag G, Morganti-Kossmann MC: Interleukin-8 released into the cerebrospinal fluid after brain injury is associated with blood-brain barrier dysfunction and nerve growth factor production. J Cereb Blood Flow Metab 1997, 17:280-289.

64. Dumont RA, Car BD, Voitenok NN, Junker U, Moser B, Zak O, O'Reilly T: Systemic neutralization of interleukin-8 markedly reduces neutrophilic pleocytosis during experimental lipopolysaccharide-induced meningitis in rabbits. Infect Immun 2000, 68:5756-5763.

65. Grütter MG: Caspases: key players in programmed cell death. Curr Opin Struct Biol 2000, 10:649-655.

66. Craighead MW, Tiwari P, Keynes RG, Waters CM: Human oligodendroglial cell line, MO3.13, can be protected from apoptosis using the general caspase inhibitor zVAD-FMK. J Neurosci Res 1999, 57:236-243.

67. Craighead M, Pole J, Waters C: Caspases mediate C2-ceramide-induced apoptosis of the human oligodendroglial cell line, MO3.13. Neurosci Lett 2000, 278:125-128

68. Buntinx M, Gielen E, Van Hummelen P, Raus J, Ameloot M, Steels P, Stinissen P: Cytokine-induced cell death in human oligodendroglial cell lines, II: alterations in gene expression induced by interferon-gamma and tumor necrosis factor-alpha. J Neurosci Res 2004, 76:846-861.

69. Hisahara S, Shoji S, Okano H, Miura M: ICE/CED-3 family executes oligodendrocyte apoptosis by tumor necrosis factor. J Neurochem 1997, 69:10-20.

70. Hisahara S, Okano H, Miura M: Caspase-mediated oligodendrocyte cell death in the pathogenesis of autoimmune demyelination. Neurosci Res 2003, 46:387-397.

71. Selmaj K, Raine CS, Farooq M, Norton WT, Brosnan CF: Cytokine cytotoxicity against oligodendrocytes, Apoptosis induced by lymphotoxin. J Immunol 1991, 147:1522-1529.

72. Schuster N, Bender H, Philippi A, Subramaniam S, Strelau J, Wang Z, Krieglstein K: TGF-beta induces cell death in the oligodendroglial cell line OLI-neu. Glia 2002, 40:95-108.

73. Takahashi JL, Giuliani F, Power C, Imai Y, Yong WW: Interleukin-1beta promotes oligodendrocyte death through glutamate excitotoxicity. Ann Neurol 2003, 53:588-595.

74. Cai Z, Lin S, Pang Y, Rhodes PG: Brain injury induced by intracerebral injection of interleukin-1 beta and tumor necrosis factor-alpha in the neonatal rat. Pediatr Res 2004, 56:377-384. 
75. Thirumangalakudi L, Yin L, Rao HV, Grammas P: IL-8 induces expression of matrix metalloproteinases, cell cycle and pro-apoptotic proteins, and cell death in cultured neurons. J Alzheimers Dis 2007, 11:305-311.

76. Brini E, Ruffini F, Bergami A, Brambilla E, Dati G, Greco B, Cirillo R, Proudfoot $A E$, Comi G, Furlan R, Zaratin P, Martino G: Administration of a monomeric CCL2 variant to EAE mice inhibits inflammatory cell recruitment and protects from demyelination and axonal loss. J Neuroimmunol 2009, 209:33-39.

77. Nordberg M, Forsberg P, Johansson A, Nyman D, Jansson C, Ernerudh J, Ekerfelt $C$ : Cytotoxic mechanisms may play a role in the local immune response in the central nervous system in neuroborreliosis. J Neuroimmunol 2011, 232:186-193.

78. Ekerfelt C, Jarefors S, Tynngård N, Hedlund M, Sander B, Bergström S, Forsberg $P$, Ernerudh J: Phenotypes indicating cytolytic properties of Borrelia-specific interferon-gamma secreting cells in chronic Lyme neuroborreliosis. J Neuroimmunol 2003, 145:115-126.

79. Bruin KF, Hommes DW, Jansen J, Tytgat GN, Wouter Ten Cate J, van Deventer SJ: Modulation of cytokine release from human monocytes by drugs used in the therapy of inflammatory bowel diseases. Eur $\mathrm{J}$ Gastroenterol Hepatol 1995, 7:791-795.

80. Harkness KA, Sussman JD, Davies-Jones GA, Greenwood J, Woodroofe MN: Cytokine regulation of MCP-1 expression in brain and retinal microvascular endothelial cells. J Neuroimmunol 2003, 142:1-9.

81. Loetscher P, Dewald B, Baggiolini M, Seitz M: Monocyte chemoattractant protein 1 and interleukin 8 production by rheumatoid synoviocytes, Effects of anti-rheumatic drugs. Cytokine 1994, 6:162-170.

82. Massengo SA, Bonnet F, Braun C, Vital A, Beylot J, Bastard J: Severe neuroborreliosis: the benefit of prolonged high dose combination of antimicrobial agents with steroids - an illustrative case. Diagn Microbiol Infect Dis 2005, 51:127-130.

83. Dong C, Davis RJ, Flavell RA: MAP kinases in the immune response. Annu Rev Immunol 2002, 20:55-72.

84. Wang $X$, Liu Y: Regulation of innate immune response by MAP kinase phosphatase-1. Cell Signal 2007, 19:1372-1382.

85. Tibbles LA, Woodgett JR: The stress-activated protein kinase pathways. Cell Mol Life Sci 1999, 55:1230-1254

86. Ramesh G, Philipp MT: Pathogenesis of Lyme neuroborreliosis: mitogenactivated protein kinases Erk 1, Erk 2 and p38 in the response of astrocytes to Borrelia burgdorferi lipoproteins. Neurosci Lett 2005, 384:112-116.

87. Jakovcevski I, Filipovic R, Mo Z, Rakic S, Zecevic N: Oligodendrocyte development and the onset of myelination in the human fetal brain. Front Neuroanat 2009, 3:5-15.

88. Brück W: The pathology of multiple sclerosis is the result of focal inflammatory demyelination with axonal damage. J Neuro/ 2005, Suppl 5:v3-v9.

89. Butts BD, Houde C, Mehmet H: Maturation-dependent sensitivity of oligodendrocyte lineage cells to apoptosis: implications for normal development and disease. Cell Death Differ 2008, 15:1178-1186.

90. Matute C, Perez-Cerda F: Multiple sclerosis: novel perspectives on newly forming lesions. Trends Neurosci 2005, 28:173-175.

91. Bradl M, Lassmann H: Oligodendrocytes: biology and pathology. Acta Neuropathol 2010, 119:37-53

doi:10.1186/1742-2094-9-72

Cite this article as: Ramesh et al:: A possible role for inflammation in mediating apoptosis of oligodendrocytes as induced by the Lyme disease spirochete Borrelia burgdorferi. Journal of Neuroinflammation 2012 9:72

\section{Submit your next manuscript to BioMed Central and take full advantage of:}

- Convenient online submission

- Thorough peer review

- No space constraints or color figure charges

- Immediate publication on acceptance

- Inclusion in PubMed, CAS, Scopus and Google Scholar

- Research which is freely available for redistribution 